\title{
Co-Ownership of Intellectual Property: \\ Exploring the Value-Appropriation and Value-Creation Implications of Co-Patenting with Different Partners.
}

\author{
Rene Belderbos, KU Leuven, UNU-MERIT \& Maastricht University \\ Bruno Cassiman, IESE Business School, KU Leuven \& CEPR \\ Dries Faems, University of Groningen \& KU Leuven \\ Bart Leten, KU Leuven, Vlerick Business School \& FWO Flanders \\ Bart Van Looy, KU Leuven \& IGS, University of Twente.
}

August 2013

\section{Acknowledgements}

The authors wish to thank Henry Chesbrough, Ashish Arora, the two anonymous referees, John Hagedoorn, Ammon Salter, and the participants in the workshop on Open Innovation: New Insights and Evidence held in London for their helpful comments. In addition, we would like to thank Esther van Zimmeren (CIR, KU Leuven) for providing feedback on the legal implications of (co-) patents and various company experts for sharing their experience and insights on co-patenting strategies and their implications. Bruno Cassiman is a research fellow of the SP-SP Research Center at IESE Business School and acknowledges partial financial support from the Spanish Ministry of Science and Innovation through project no ECO2009-13169, the Catalan Government Grant no 2009-SGR919. Bruno Cassiman and Bart Van Looy acknowledge partial financial support from IMPH006 and Bart Leten and Rene Belderbos from FWO Flanders (project G.0468.09). 


\title{
Co-Ownership of Intellectual Property: Exploring the Value-Appropriation and Value-Creation Implications of Co-Patenting with Different Partners.
}

\begin{abstract}
Combining both interview data and empirical analyses at the patent and firm levels, we explore the value-appropriation and value-creation implications of $R \& D$ collaboration resulting in the co-ownership of intellectual property (i.e. co-patents). We make an explicit distinction between three different types of co-patenting partners: intra-industry partners, inter-industry partners, and universities. Our findings indicate that the value-appropriation challenges of IP sharing are clearly evident with intra-industry co-patenting, where partners are more likely to encounter overlapping exploitation domains. Co-patenting with universities is associated with higher market value, since appropriation challenges are unlikely to play a role and collaboration may signal novel technological opportunities. Although we find some evidence that co-patenting corresponds to higher (patent) value, patents co-owned with firms are significantly less likely to receive self-citations, indicating constraints on the future exploitation and development of co-owned technologies.
\end{abstract}




\section{Introduction}

The open-innovation paradigm conceives Research and Development (R\&D) as an open system where firms can benefit from a variety of collaborative activities with external knowledge partners (Chesbrough 2003, 2006). Scholars (e.g. Belderbos, Carree \& Lokshin, 2004b; Cassiman \& Veugelers, 2006; Chesbrough, 2003; Faems, Van Looy \& Debackere, 2005; Laursen \& Salter, 2006) emphasize the need for inter-organizational R\&D collaboration, which facilitates the synergistic blending of external and internal ideas into new products, processes and systems. At the same time, the appropriation challenges that such open-innovation models entail are being increasingly acknowledged. The more that firms collaborate with external partners, the more difficult it becomes to appropriate the outcomes of such collaborative efforts for the partners involved (Di Minin \& Faems, 2013; Henkel, 2006; Chesbrough \& Rosenbloom, 2002). Laursen and Salter (2005) therefore refer to the 'paradox of openness', which maintains that creating innovations benefits from openness while commercializing innovations requires appropriability.

In this paper, we focus on co-patenting as a potential window for investigating this openness paradox. In practice, co-patenting implies the joint ownership of collaborative outcomes. Previous research on this particular phenomenon emphasizes the disadvantages of co-patenting. Hagedoorn (2003), for instance, labels co-patenting as a second-best strategy that firms prefer to avoid. Belderbos et al. (2010) find a negative relationship between the share of co-patents in a firm's patent portfolio and its financial performance ${ }^{1}$. At the same time, these studies provide evidence that co-patenting is no fading trend. The number of coowned patents in the US increased steadily over time (Hagedoorn, 2003; Goossen, 2013) and the share of European Patent Office (EPO) co-patents in the patent portfolios of R\&Dintensive firms remained stable between 1996 and 2003 (Belderbos et al., 2010).

\footnotetext{
${ }^{1}$ Fosfuri et al. (2012) on the other hand suggest that co-patenting may be a tool to enhance effective collusion in product markets.
} 
In sum, whereas studies stress the disadvantages of co-patenting, we duly note that co-ownership of intellectual property (IP) remains an empirically relevant strategy for companies developing technology jointly. The purpose of this paper is to explore the role and performance implications of co-patenting in the setting of collaborative R\&D activities. In particular, we focus on the potentially different implications of co-patenting with different types of collaborative partner, distinguishing between intra-industry, inter-industry and university partners. We proceed in two steps. First, in order to explore the advantages and disadvantages of IP sharing in collaborative R\&D activities, we utilize interviews with 10 IP managers from large organizations engaged in $R \& D$ collaboration and co-patenting on an international level. In general, these interviews confirm that co-ownership of IP may indeed restrict firms' ability to fully appropriate the market potential of knowledge derived from collaborative R\&D. At the same time, they suggest that the value-appropriation challenges of co-patents heavily depend on the type of partner involved in the collaborative activities. Finally, our interview findings suggest that ex-ante negotiations on co-patenting arrangements may have a beneficial impact on the value-creation dynamics in collaborative R\&D.

In the second step of our study, we rely on panel data from 164 European, US, and Japanese firms to test some of the insights that emerged from our interviews. Our quantitative analyses show a significantly negative relationship between the share of copatents with intra-industry partners and the firm's performance - which we measure as market value (Tobin's q). Co-patenting with universities increases market value. At the patent level, we observe that co-patents on average tend to receive more patent citations. More detailed analyses reveal a strong negative partial correlation between co-patenting with firm partners and the self-citations of focal firms, whereas a positive correlation is observed between co-patenting and firms' other citations. 
Together, these results suggest that, although co-owned technologies may be associated with greater value creation, individual firms may face liabilities in appropriating returns from these technologies and in deploying them in their subsequent $R \& D$ and patenting efforts. These liabilities are most pronounced in intra-industry partnerships where a high probability of overlapping exploitation domains for co-owned technologies is present. Our results are consistent with the view that appropriation issues play a more limited role in inter-industry partnerships - where exploitation domains are more likely to differ - and in partnerships with universities, which are less likely to actively engage in (competing) commercialization trajectories.

Jointly, these findings provide a nuanced perspective on the role of co-patents in addressing the openness paradox in collaborative R\&D activities. At the same time, we identify important avenues for future research on joint IP ownership in open-innovation settings, emphasizing the need to further explore both the value-appropriation and valuecreation implications of collaborative IP arrangements.

In the next section, we turn to existing literature and our interviews to explore the role and performance implications of co-patenting. Our data and methods are discussed in Section 3. Empirical results are presented in Section 4 followed by a discussion in Section 5.

\section{Exploring the Role and Performance Implications of Co-Patenting.}

A co-patent is a patent owned by two or more assignees. As such, co-patent arrangements are clearly different from other multi-party patent arrangements such as cross licenses, pooled patents, and patent infringement arrangements. ${ }^{2}$ In the case of co-patents, both applicants have the right to exploit the invention on their own behalf. At the same time, considerable differences between national patent offices can be observed regarding transfer of ownership and license agreements. By default, co-patents in the USPTO imply considerable degrees of

\footnotetext{
${ }^{2}$ See Hagedoorn (2003) for a discussion of the legal differences between co-patenting and other multi-party patent arrangements.
} 
freedom for the co-applicants involved: transferring ownership as well as engaging in license agreements does not imply consent from the other owners (35 U.S.C. 262 joint owners ${ }^{3}$ ). This means that, if company A and B are co-owners of a patent, company B has the right to license the patent to company $\mathrm{C}$, a potential competitor of company A, without needing the consent of company A (Carlson \& Barney, 1999; Paradiso \& Pietrowski, 2009). In Europe, however, consent in the case of transferring ownership and/or engaging in license agreements is the rule rather than the exception. ${ }^{4}$ Contractual agreements between partners can complement and alter the default arrangements, in terms of both transfer of ownership and license agreements.

Both legal and management scholars (e.g. Hagedoorn, 2003; Paradiso \& Pietrowski, 2009; Merges \& Locke, 1990; ; Fosfuri et al., 2012) have emphasized the complexities that co-patenting entails. At the same time, when inspecting the evolution of co-patenting intensity over time, a steady increase in co-patenting is observed - coinciding broadly with the overall growth rates in patent activity (Hagedoorn, 2003). Thus, the proportion of copatents remains stable over time (Azollea, Landoni \& Van Looy, 2012; Belderbos et al., 2010).

To address the constraints placed on internal technology development capabilities, firms rely heavily on collaboration with external partners to jointly develop new technologies (Ahuja, 2000). Because of these complexities, collaborative partners generally prefer to divide the intellectual ownership resulting from collaborative $R \& D$ among the partners involved (Hagedoorn, 2003). However, scholars have identified particular circumstances in which partners are likely to adopt joint IP ownership of collaborative $R \& D$ outputs. Hagedoorn (2003), for instance, argues that, in certain types of R\&D collaboration (i.e. small

\footnotetext{
3 'In the absence of any agreement to the contrary, each of the joint owners of a patent may make, use, offer to sell, or sell the patented invention within the United States, or import the patented invention into the United States, without the consent of, and without taking account of, the other owners.'
}

\footnotetext{
${ }^{4}$ AIPPI (2007) Summary Report: The impact of co-ownership of Intellectual Property Rights on their Exploitation.
} 
scale, informal partnerships), it may be very difficult to divide the intellectual property between the partners. In such circumstances, partners are likely to rely on co-patenting as a second-best option. In addition, Teng (2007) argues that, when R\&D outputs have the potential to become a core competency for one partner and when a substantial risk exists that the other partner could abuse individually-owned IP for strategic reasons, the concerned partner is likely to prefer joint IP rights to splitting the ownership in two. Finally, Hagedoorn, Van Kranenburg, and Osborn (2003) provide evidence that firms engaged in co-patenting activities in the past are more likely to adopt co-patenting with subsequent collaborative activities. ${ }^{5}$ This latter finding suggests that the learning experience of effectively arranging and managing co-patents makes firms more likely to employ them in subsequent collaborative efforts.

Despite the complexities and challenges of co-patenting, co-ownership of collaborative R\&D outcomes occurs in particular circumstances. In order to further explore the role and performance implications of co-patenting, we first conducted interviews with nine IP experts operating in multinational firms and one IP expert from an internationally renowned knowledge institute. We asked interviewees to reflect on (i) the benefits and liabilities of co-patenting for collaborative R\&D activities, and (ii) the potential performance implications of co-patenting. Then, we systematically compared interview content with existing literature on co-patenting. In line with previous research, the interviews showed clearly that co-patenting involves important value-appropriation risks. At the same time, however, interviewees indicated that the ex-ante negotiation of co-patenting arrangements may affect the value-creation processes in collaborative R\&D activities. Below, we provide a detailed discussion of these two aspects of co-patenting.

\subsection{Value-Appropriation Implications of Co-Patenting.}

\footnotetext{
${ }^{5}$ Many of our sample firms engage in subsequent patenting over time, confirming the findings by Hagedoorn et al. (2003) that experience is an important determinant of co-patenting.
} 
Whereas individually-owned patents create a temporary monopoly for the patent owner, copatenting resembles a duopoly (or tight oligopoly) in which the joint owners can compete against each other (Hagedoorn, 2003). In our interviews, it was acknowledged that, compared to fully owned patents, co-ownership of knowledge creates fewer opportunities for realizing monopoly rents. In addition, it was stressed that sharing ownership of knowledge 'creates uncertainty over the control that each co-owner has of the co-owned IP.' Several examples were provided to illustrate such value-appropriation risks:

'Under Swedish law, a co-owner has the right to get rid of the patent and sell his part of the patent ownership. The other co-owner can bid for the rights, but the selling coowner has the right to sell his ownership to the highest bidder. This can be a competitor, who uses the patent to compete with the other co-owner.'

'There is always a risk that they [i.e. patent co-owners] will go bankrupt and their rights to the co-patents are sold.'

Prior research on the performance implications of co-patenting has largely ignored the type of partner involved in the co-patenting activities. Interviewees, however, emphasized that the challenges of appropriating value from co-patents heavily depends on the type of partner involved. First of all, they indicated that value-appropriation concerns are likely to be low when ownership of knowledge is shared with universities. When the partner is a university, the risk of this partner emerging as a competitive threat to the focal firm is rather limited because universities often lack the incentives and abilities to commercially exploit the co-owned knowledge:

'The business of universities is not to compete with companies. Universities are rather in the business of educating people, developing their faculty and doing basic research. Hence, markets are likely less concerned when companies co-own patents with universities.'

In addition, interviewees stressed that, when they engage in collaboration with universities, 'it is a standard procedure to contractually negotiate that universities do not have 
the right to license such co-owned knowledge to our competitors.' In this way, firms can mitigate the risk of co-patenting with universities indirectly triggering increased competition.

Regarding co-patenting with private firms, interviewees emphasized that the valueappropriation consequences of co-patenting depend on whether partners are active in similar domains. In particular, it was stressed that, when partners are active in different industries and markets, there is a relatively high likelihood that they will use the co-owned knowledge for different exploitation purposes:

'When we collaborate with suppliers, a standard agreement is that we get the right to exploit the IP within the application domain of our products, whereas the partner can exploit the IP in other domains that are outside our commercial interest.'

In contrast, when partners are active within the same industry, the risk that they will deploy the co-owned knowledge for similar purposes is higher, implying a risk of intensified competition that could jeopardize value appropriation.

'Co-patents with competitors trigger difficult discussions [about exploitation] afterwards.'

Based on these insights, we expect co-patents with intra-industry partners, where the risk of overlapping application domains is relatively high, to create more challenges in appropriating value than co-patents with inter-industry partners or with universities. As information on co-patenting activities disseminates, analysts and investors are likely to take these consequences into account in their assessment of future profitability prospects. This implies that the negative association of co-patenting with market valuation, which prior research has identified (e.g. Belderbos et al., 2010), should primarily be a feature of copatenting activities with intra-industry partners.

\subsection{Value-Creation Implications of Co-Patenting.}

Our interviews also suggest that negotiating co-patenting arrangements ex-ante may influence the collaboration processes and, hence, the value creation resulting from collaboration. First, 
following the open-innovation paradigm, organizations engaged in collaborative R\&D efforts have the opportunity to synergistically combine their complementary knowledge sources. This facilitates the generation of technological inventions that organizations could not achieve on their own (Carson et al., 2003; Vanhaverbeke, 2006). At the same time, it is emphasized that, in order to effectively realize such synergies, intensive interaction between partners is necessary (Doz, 1996; Faems, Janssens \& Van Looy, 2007). Existing studies on inter-firm $R \& D$ collaboration, however, signal that the willingness of partnering firms to engage in intensive interaction is often limited by ex-ante concerns to appropriate knowledge. Madhok and Tallman (1998: 332), for instance, argue that 'such interaction acts as a doubleedged sword since, in order to attain the underlying purpose of transferring, absorbing, and, generally, more effectively combining complementary capabilities at the heart of the collaboration, the firm also exposes critical resources and capabilities to transmission through the alliance to the partner firm.' In a similar vein, Heiman and Nickerson (2004: 401) maintain that intensive and fine-grained interaction 'increases the likelihood that economically valuable knowledge [...] is expropriated.' In other words, these scholars following a transaction cost logic - suggest that a firm's ability to achieve joint value creation in collaborative projects could be restricted because of ex-ante concerns that the other partner might opportunistically appropriate the knowledge resulting from such interaction.

In our interviews, IP experts referred to the importance of ex-ante contractual IP allocation procedures to mitigate such knowledge appropriation concerns. In particular, they explained that, at the start of the collaboration, partners tend to contractually define the existing knowledge domains of both partners based on their current technological expertise and capabilities. In addition, they contractually agree that, when collaborative R\&D efforts result in intellectual property in one of the unique knowledge domains, the domain owner will become the sole owner of the patent. At the same time, several interviewees signaled the 
likely presence of a 'gray [knowledge] zone' where it is difficult to determine ex-ante who should be the owner of the intellectual property. For these particular knowledge domains, interviewees pointed to the relevance of co-patenting arrangements, where partners contractually agree to share the ownership of knowledge jointly generated.

'We typically agree that co-developed knowledge that falls outside the direct scope of the collaboration and the application domains of the collaboration partners is coowned; such IP holds the promise for us, perhaps in collaboration with our partner, to build a new business'

Based on these observations, we expect that, when partners contractually define the option of co-patenting for knowledge domains that are non-partner specific, ex-ante knowledge-appropriation concerns are mitigated, resulting in a greater willingness to effectively engage in joint value-creation activities. Recent findings by Carson and John (2013) provide initial support for these observations. Analyzing 147 R\&D outsourcing contracts, they find that 'clients who share property rights with their contractors face reduced opportunism during project execution' (Carson \& John, 2013, p. 1065).

Interviewees also referred to the relational impact of ex-ante co-patenting arrangements in collaborative R\&D activities. Hagedoorn et al. (2003, p.72) were to the fore in arguing that 'joint patenting expresses a mutual relational trust between separate companies.' In a similar vein, our interviewees emphasized that co-patents could contribute to increased levels of trust between collaborative partners, thereby strengthening the intensity of cooperation between the partners involved:

'Up-front co-patent arrangements are helpful because they reinforce the mutual commitment of both partners.'

'Co-patent arrangements provide a signal of trust which strengthens the connection between the partners and stimulates cooperation.'

'As a large company, we sometimes use co-patents to reduce the distrust of small partners. It is about creating goodwill and the necessary trust to increase the probability of collaborative success.' 
In sum, we find strong indications that co-patenting arrangements can reduce ex-ante knowledge appropriation concerns and, subsequently, increase the level of trust between partners in the collaboration. In line with existing literature on collaborative R\&D (Dyer \& Singh, 1998; Cassiman \& Veugelers, 2006; Faems et al., 2008), we expect that the willingness of partners to effectively combine their complementary knowledge will be higher in such circumstances, increasing the probability of effective joint value creation.

\section{Data and Methods}

To more formally corroborate these value-creation and value-appropriation challenges of copatenting we conduct two types of empirical analysis. At the patent level, we explore whether the value of a patent (measured on the basis of citations received) differs systematically between the three types of co-patent on the one hand and the single firm-owned patent on the other hand. In a second empirical model, we examine the relationship between the copatenting activities of firms and a forward-looking measure of firms' financial performance (i.e. Tobin's q) as an indicator of value appropriation.

We constructed a panel dataset (1995-2003) consisting of the technological activities and financial performance of 164 R\&D-intensive European, US and Japanese firms. These firms are active in five broadly defined industries: (i) engineering and general machinery, (ii) pharmaceuticals and biotechnology; (iii) chemicals; (iv) IT hardware (computers and communication equipment); and (v) electronics and electrical machinery. The firms are drawn from the 2004 EU industrial R\&D investment scoreboard, which provides listings of the most R\&D-intensive European, US and Japanese firms across all industries. The firms are the largest R\&D spenders in each industry and in each of the home countries.

We rely on firms' patents to examine co-patenting behavior and to construct measures of technological performance based on patent value (i.e. citations). There are numerous advantages to the use of patent indicators (Pavitt, 1985; Basberg, 1987; Griliches, 1990; Hall, 
Jaffe \& Trajtenberg, 2005): patent documents contain highly detailed information on content and ownership of patented technology; they cover a broad range of technologies; patent data are 'objective' in the sense that they have been processed and validated by patent examiners; and patent data are publicly available. Like any indicator, patents are subject to a number of limitations: not all technological activities are patented and patent propensities vary across firms and industries. ${ }^{6}$

We collected firm patent data at the consolidated level: i.e. all patents of the parent firm and its consolidated (majority-owned) subsidiaries are included. For this purpose, we used lists of subsidiaries included in corporate annual reports, $10-\mathrm{K}$ reports filed with the SEC in the US and, for Japanese firms, information on foreign subsidiaries published by Toyo Keizai in the yearly 'Directories of Japanese Overseas Investments'. The consolidation was conducted on an annual basis (1996-2003) to take account of changes in the group structure of the firms over time. Using consolidated patent data is important in order to obtain a complete picture of the technological activities of firms, since a significant proportion of patents are not filed under the parent firm name. In our sample, $18 \%$ of firm patents, on average, are filed under the name of firm subsidiaries or name variants of the parent firm.

In this study, we used patent data from the European Patent Office (EPO). European patent data are preferred to the more commonly used data from the United States Patent and Trademark Office (USPTO). Typically, EPO patents are considered a better indication of valuable technological activities: the cost of patenting is two to five times higher at the EPO than at the USPTO; the workload of patent examiners is four times smaller at the EPO than at the USPTO; and the EPO has a 20-30\% lower patent-granting rate than the USPTO (Van Pottelsberghe de la Potterie \& François, 2006; Quillen \& Webster, 2001; Jaffe \& Lerner, 2004). Since our interest centers on IP sharing and appropriation, we focus our analysis on

\footnotetext{
${ }^{6}$ As reported by Levin et al (1987) and Arundel and Kabla (1998), patent propensities are high in our five sample industries, making patents a meaningful indicator of firms' technological activities in these industries.
} 
patent applications subsequently granted and their citations. We classify patents by the year of application. Patent-granting decisions at the EPO take five to six years on average (Harhoff \& Wagner, 2009), so that, even with our time frame of analysis (1996-2003), there is a degree of right truncation of patent counts. ${ }^{7}$ We note that this does not necessarily affect citations received since patent applications are published well before patents are granted ${ }^{8}$, and granted patents receive citations well before the grant date. We control for truncation by including year dummies in our empirical models for the application year of the patent.

We used information on the ownership of the patents to distinguish between individually-owned and co-owned patents. A patent is considered co-owned when it operates under joint ownership with an actor entirely independent of the consolidated focal firm (another firm, or a university). Patents jointly owned by firms and individual persons have been excluded since we cannot establish whether these individuals are employed by the focal firm or not. Patent applicant (assignee) names referring to individual persons, firms and universities are identified by sector allocation algorithms (source: Van Looy, Du Plessis \& Magerman, 2006).

We defined the corporate co-owners of patents as intra-industry partners or interindustry partners based on the main sector(s) in which the assignee firms operate. To determine the main sector(s) of firms, we identified the technology class(es) in which the firm filed the majority of its patents. ${ }^{9}$ Technology classes are linked to sectors via the concordance table developed by Schmoch et al. (2003). This table relates technology fields at

\footnotetext{
${ }^{7}$ For granted patents applied in 1996, the average granting decision took 5.25 years, with $25 \%$ of grants having a granting lag of seven years or longer (source: our own calculations based on data from the PATSTAT database). In our analysis, dropping the years 2002 and 2003 to reduce truncation in patent grants and citations did not affect the empirical results.

${ }^{8}$ The EPO guidelines states that European patent applications are published 18 months after filing with the EPO or 18 months after the priority date. However, the reality is somewhat different. Based on our own calculations on all EPO applications filed in the period 1990-2005, we found that the average publication lag of EPO patent applications varied between two and three years. This is also related to the increasing popularity of PCT filings, which introduces an additional time lag between application and publication.

${ }^{9}$ In the case of a firm with more than one top patenting class (same number of patents), it is assigned to multiple sectors. This is the case for approximately $8 \%$ of our observations (firm-year observations).
} 
the IPC 4-digit level to one of 44 manufacturing sectors. ${ }^{10}$ The sectors are a combination of 3-digit and (some) 2-digit NACE industries, with more sub-classes available for high-tech industries. Our sample firms have their main activities in 33 of the 44 industries. The ten most frequently assigned sectors are: pharmaceuticals (NACE 24.4), office machinery and computers (NACE 30), basic chemicals (NACE 24.1), electronic components (NACE 32.1), signal transmission/telecommunications (NACE 32.2), special purpose machinery (NACE 29.5), energy machinery (NACE 29.1), TV and radio receivers (32.3), non-specific purpose machinery (NACE 29.2), and motor vehicles (NACE 34). The same procedure is used to identify the main sectors of partnering firms (co-assignees of co-patents), using assignee name harmonizing algorithms (Van Looy et al, 2006) and the consolidation exercise to identify patents belonging to the same firm in the patent database. If the focal firm and the partner firm are active in the same sector, the co-patent is defined as intra-industry; in all other cases, it is defined as inter-industry. An example of an intra-industry co-patent is EP1058547, which is co-owned by Eli Lilly (focal firm) and Shionogi and Company; both firms have pharmaceuticals as their main sector. Co-patent EP0687499 is an example of an inter-industry co-patent. It is co-owned by BASF (focal firm) and Daimler Chrysler, which have 'basic chemicals' and 'motor vehicles' as their main industry, respectively. Our implicit assumption is that the likelihood of future competitive interaction between intra-industry partners is larger than in the case of inter-industry partners.

Patented technologies differ in their technical and economic value (Schankerman \& Pakes, 1986; Albert et al., 1991; Harhoff et al., 1999). Patent forward citations have been advanced as a measure for the value of patents (e.g. Trajtenberg, 1990; Henderson, Jaffe \& Trajtenberg., 1998; Hall et al., 2005). We apply a fixed 4-year window to calculate the

\footnotetext{
${ }^{10}$ An alternative method to identify the main sector(s) of the partnering firms would be to consult financial databases such as Compustat, Worldscope and Orbis, and examine the SIC codes listed in these. However, these databases do not cover all the patent assignees (in total, we have 2495 different co-assignees) and patent co-assignee names. Company legal names reported in financial databases are often not aligned, frequently requiring manual coding.
} 
number of citations that patents receive in order to establish a comparable citation window across patents. We include all patent citations (from patents filed in various patent offices) and equivalents within the patent family (patent documents that share priority dates). Citations are calculated on the PATSTAT database (April 2012 version), which contains citation information for patents from all major patent offices worldwide (EPO, USPTO, JPO) and a large set of national patent offices. While citations can be suggested by patent applicants, it is always the examiner who decides which citations are included in patents ${ }^{11}$ (Van Looy et al., 2007). We also make a distinction between self-citations by the focal firms and non-self-citations. Self-citations are citations made by the same focal firm and its consolidated subsidiaries in subsequent patent applications. The distinction between selfcitations and non-self-citations allows us to investigate whether the patent-owning firm rather than other firms builds upon a patented invention in later technological activities (Rosenkopf \& Nerkar, 2001; Sorenson and Stuart, 2000). Forward self-citations have been found to be a better predictor of the economic value of patents than non-self-citations (e.g. Hall et al., 2005; Belenzon, 2011) since self-citations indicate that the patents are a source of future development and exploitation by the firm itself.

\subsection{Patent Level Analysis.}

In the patent level analysis, we examine the characteristics of the firms' patent grants, including their co-patent status, applied for between 1996 and 2003. Together, the 164 firms account for 85,706 patent applications during the observed time period, which were granted subsequently. The empirical model at the patent level uses the number of forward citations as the dependent variable. We apply Poisson regression models with robust standard errors and firm fixed effects to analyze the partial correlations between forward citations and whether

\footnotetext{
${ }^{11}$ Alcacer and Gittelman (2006) and Alcacer, Gittelman and Sampat (2009) demonstrate that the central role of patent examiners has implications when conceiving patent citations as 'knowledge flows'. This, however, does not affect the interpretation of our results, since our analysis considers citations as qualifications of the underlying inventions (rather than direct knowledge flows). As argued by Van Looy et al. (2007), front page references hence signal relevance or content relatedness.
} 
the patent is co-owned (by different types of partner). We differentiate the dependent variable between self-citations and non-self-citations received to explore differences in citation patterns and future exploitation of patented technologies in greater detail. ${ }^{12} \mathrm{We}$ make an important caveat with this analysis. Since the co-patent status combines information on R\&D collaboration and its IP sharing arrangement, our models do not allow us to parse the implications of IP sharing per se. In order to examine this more precisely, we would need to identify patents that are the result of collaborative R\&D but are owned by a single firm information that is not readily available.

The explanatory variables of interest in the model are dummy variables indicating whether the patent is a co-owned patent with an intra-industry, inter-industry or university partner. The analysis includes a full set of 3-digit IPC technology field dummies (a patent can be assigned to multiple IPCs and, hence, may have multiple dummies with value 1), year of application dummies, and parent firm dummies. In addition, the models include a set of other characteristics identified as relevant in prior work on patent citations: the number of technology fields in which the patent is classified, the number of non-patent citations (including citations in the scientific literature), the number of backward patent citations and the number of inventors listed on the patent. The number of technology fields is counted on the level of the 3-digit International Patent Classification (IPC) codes listed on the patent. A broader technological patent scope could determine the extent of patent protection and monopoly power and, thus, the economic value of an invention (Scotchmer, 1991). More IPC classes covered by the patent could also affect the likelihood of being cited, since the patent is relevant to a larger part of the technology landscape. The number of non-patent citations (references primarily to scientific literature) may be associated with a higher number of received citations because the act of publication allows the ideas underlying the patent to be

\footnotetext{
${ }^{12}$ We thank an anonymous reviewer for suggesting this additional analysis.
} 
diffused more broadly and rapidly (Fleming \& Sorenson, 2004) or because these patents are perceived to have greater potential importance (Harhoff et al., 2003). Similarly, we introduce the number of backward patent references to control for unobserved factors affecting citation behavior (Reitzig, 2004). Finally, we include the number of inventors listed on the patent as an additional control because more inventors may lead to faster and greater diffusion of the tacit and complex knowledge underlying the patent, resulting in different forward citation patterns. This measure is also used to control for the resources invested in developing the technology and is, therefore, correlated with the number of organizations involved in the development of the technology (i.e. co-patenting).

\subsection{Firm-Level Analysis.}

The second empirical model examines the relationship between the co-patenting activities of firms and a forward-looking measure of firms' financial performance, Tobin's q. We use a specification of the market value function that is predominant in the literature: an additively separable linear specification (see e.g. Griliches, 1981; Hall et al., 2005). The key independent variables measure information available to financial analysts that affects their assessment of the future income streams and stock value of the firm. Financial analysts base their forecasts on public records and company filings (e.g. patents) and on their understanding of how value is created. Analysts' forecasts have a significant impact on the price and trading value of firm stocks (Benner \& Ranganathan, 2012). We follow prior literature on the market valuation effects of R\&D and patents (e.g. Hall et al., 2005; Arora, Belenzon \& Rios, 2013) by calculating stock variables for all R\&D and patent-related variables (including patent data from 1978 and R\&D data from 1985). In the case of patents, the time lag before information reaches investors is of importance. We classify patent grants at the year of application (the year the collaborative R\&D was conducted). However, EPO patent applications generally take a minimum of 1.5 years and usually $2-3$ years before they 
are published by the patent office and become fully visible to investors. On the other hand, the publication date is not always representative of the timing of patent disclosure, as firms may disclose their patent filings earlier to investors. Generally, we can expect that patents filed in year $t$ are most likely to affect market valuations in $t+2$ or $t+3$. As a first step, our approach has been to explore empirically the effects of time lags between patent filings and market valuation effects. Estimating models with various time lags (from contemporaneous measures to t-3) for the patent variables, we found broadly consistent results for all models, but with coefficients for the patent variables that were higher the longer the time lag. We present the results of models with 2-year lagged patent variables, since adding further lags reduces the number of observations for firms in the dataset, without providing any appreciable gain in the precision of the patent variable estimates.

While the 2-year lag helps to alleviate concerns about reverse causality (due to the phenomenon of the delayed effects of patent applications on market value), our analysis cannot rule out endogeneity stemming from unobserved heterogeneity. We, therefore, interpret our results as partial correlations (associations) rather than causal relationships. Given the 2-year time lag and the panel data covering 1995-2003, we analyze the relationship between co-patenting and market value over the period 1997-2003. ${ }^{13}$ The dataset contains 1059 observations on 164 firms. We follow prior studies in estimating the market value model with ordinary least squares and error terms clustered at the firm level.

Finally, we again note that co-patenting intensities combine information on collaboration strategies (including potential value creation) with IP sharing arrangements. It is not possible to directly compare co-patenting strategies with the effect of collaboration strategies without such IP sharing; we are not able to identify which patents were due to

\footnotetext{
${ }^{13}$ Results of the models with other lags are available upon request. We did not uncover similar lag structures for the (very stable) technology diversification variable. We include contemporaneous measures for this variable.
} 
collaborative $\mathrm{R} \& \mathrm{D}$ but led to exclusive IP arrangements concerning individually-owned patents. At the same time, we may expect the effects of co-patenting on the market value analysis to significantly reflect appropriation issues as perceived by the market. Positive performance effects from collaboration per se are, in part, already reflected in higher patent value (citations and self-citations) and a higher incidence of patenting - which we have controlled for in the analyses.

The dependent variable in the financial performance analysis is (the natural logarithm of) Tobin's q, i.e. the ratio of the market value of a firm and the replacement (book) value of the firm's assets. A firm's market value is defined as the sum of market capitalization (share price multiplied by the number of common shares outstanding at the end of the year), preferred stock, minority interests, and total debt minus cash. In contrast to current profit indicators (e.g. sales, net profits, ROA), Tobin's q is a forward-looking indicator that contains the stock market's assessment of a firm's future financial results from current technological activities. This forward-looking aspect is important since returns from technological activities often become manifest only several years after the activities have taken place (Czarnitzki, Hall \& Oriani, 2006). Information on the market and book value of firms is collected from financial databases (Worldscope and Compustat) and annual company reports.

The key explanatory variables of interest are variables reflecting the intensity of copatenting activities with different partners. We include three indicators of co-patenting activities representing the degree to which the firm is engaged in co-patenting with intraindustry, inter-industry and university partners. Each of these variables measures the share of a firm's total granted stock of patents from that particular co-patenting activity, with a twoyear lag. Patent stocks were calculated as a perpetual inventory of a firm's past and present granted patents with a constant depreciation rate $(\delta)$ of $15 \%$, as is common practice in the 
literature (see Griliches and Mairesse, 1984). We trace back EPO patent grants from the foundation of the EPO (1978)

As control variables, we include four indicators of the firm's technological activities: $\mathrm{R} \& \mathrm{D}$ intensity ( $R \& D$ expenditures/assets), patent propensity (patents/R\&D expenditures, with a two-year lag; R\&D expenditures in million Euros), patent citations (citations/patents, number of citations per patent), and the ratio of self-citations to total patent citations (selfcitations/citations). Firms that spend more money on technological activities (R\&D intensity) and are more successful in these activities (patent propensity) are expected to realize greater future income streams and a higher market valuation. The number of citations received is correlated with the (commercial and technical) value of the firms' technology portfolio, as confirmed by prior studies relating the stock market value of firms to measures of their technological activities (Griliches, 1981; Pakes, 1985; Blundell, Griffith, \& van Reenen, 1999; Hall et al, 2005). R\&D and citation variables are constructed using the same formula as for patent stocks and the same depreciation rate $(\delta)$ of $15 \%$. For the construction of R\&D stocks, listings of annual R\&D expenditures going back to 1985 are used. To calculate initial R\&D stock values, an annual R\&D growth rate of $8 \%$ is applied ${ }^{14}$ (e.g. Hall \& Oriani, 2006; Hall, Thoma \& Torrisi, 2007). Annual R\&D expenditures and asset data have been deflated using GDP deflators.

Second, we control for technology diversification by including the (natural logarithm of the) number of 3-digit technology classes in which the firm is active (technology diversification). Third, we include a set of 17 NACE 2-digit dummy variables to control for industry differences. Firms belonging to different sectors face different competitive pressures and opportunities, which may translate into performance differences. Fourth, we include home country (US, Japan, and 11 European countries) and year (1996-2003) dummies to

\footnotetext{
${ }^{14}$ This growth rate corresponds closely to the median annual growth rate of R\&D in our sample $(7.74 \%)$.
} 
control for differences in macro-economic trends across time and countries that may impact the stock market valuation of firms. Finally, we control for firm size by including the natural logarithm of the firm's total assets. We note that firm size and R\&D intensity have been identified as key drivers of collaborative agreements (e.g. Tether, 2002; Belderbos et al, 2004a) and may indirectly help to disentangle the effects of co-patenting from the possible confounding effects of R\&D collaboration.

\section{Empirical Results.}

\subsection{Patent-Level Analyses.}

Table 1 shows the pattern of co-patenting activities by the firms in our sample over the period 1995-2003. The number of granted patent applications hovers around 10,000 to 11,000 but starts to decline from 2001 due to the truncation effect of grant lags. Truncation appears somewhat stronger for inter-industry co-patents in 2002-2003. Co-patenting with interindustry partners is the most prevalent and makes up 1.5-2\% of firms' patents; intra-industry co-patents account for $0.9-1.5 \%$. In contrast, university co-patenting is rather rare and amounts to only 10 to 20 cases per year (0.1-0.2\% of total patents). The percentages display a relatively stable pattern of co-patenting over time of approximately $3 \% .^{15}$

\section{INSERT TABLE 1}

Table 2 presents the empirical results of the Poisson regression models concerning the number of citations a patent receives. Model 1 includes the dummy variables (indicating whether the patent is a co-patent or not) and sets of 3-digit technology field, firm, and year dummies. Model 2 adds other patent characteristics, with the exception of the number of inventors - the patent characteristic correlated with co-patent status. Model 3 also adds the

\footnotetext{
${ }^{15}$ This percentage is below what can be observed for the EPO patent system as a whole; the difference is due to 1 ) the exclusion of co-patenting with individuals 2) the exclusion of co-patenting with assignees/patent holders belonging to the same firm. While the latter are co-patents in a strict sense, they are not due to interfirm R\&D collaboration and IP sharing.
} 
latter variable. Models 4 and 5 present the comparative results of the specification in Model 3 for the alternative dependent variables, 'self-citations' and 'non-self-citations'.

\section{INSERT TABLE 2}

The empirical results reported in Model 1 show that, controlling for technology field, patenting firm and year of application, co-owned patents with partner firms (intra-industry or inter-industry) are significantly correlated with higher forward citation rates. The coefficients imply an $11-13 \%$ citation premium for co-patents. The coefficient for university co-patenting is relatively large but not significantly different from zero. ${ }^{16}$ In Model 2, the additional patent characteristics, with the exception of the number of technology classes, have positive coefficients and are statistically significant, while the co-patenting coefficients remain largely unchanged. When the number of inventors is included in Model 3, however, the coefficients on co-patents are sharply reduced and become insignificant, while the coefficient on the number of inventors itself is positive and highly significant. While these findings are not in conflict with the notion that IP sharing may have positive value creation effects, in general it would appear difficult to disentangle the effect of co-patenting from the 'number of inventors' effect where co-patents are associated with larger inventor teams.

In Models 4 and 5, the empirical results reveal interesting contrasts. Whereas copatents do appear to receive more citations from other firms (12-14\%), co-patenting with other firms is associated with a significantly smaller number of self-citations (in the range of $32-48 \%$ ). At the same time, university co-patenting is not significantly associated with a greater or smaller incidence of self-citations and non-self-citations. The positive effect on non-self-citations may have a natural explanation: compared with focal firms' individuallyowned patents, co-patents with other firms will increase the probability that these partner

\footnotetext{
${ }^{16}$ The non-significance of university co-patents may be partially due to the small number of observations in the sample, which renders it difficult to estimate the coefficient with precision.
} 
firms cite the patent in their future technology development efforts. This is consistent with the finding by Mowery, Oxley and Silverman (1996) that alliance partners tend to cospecialize their patenting and citation behaviour over time and the finding by Goossen (2013) that the total number of citations made by all patent co-assignees for a co-patent are higher than the number of citations received by an individually-owned patent. More salient is the strongly negative effect on self-citations. This suggests that firms, in their future $R \& D$ efforts, build less on co-owned inventions compared to individually-owned inventions. This interpretation is in line with the notion of appropriation complexity associated with shared technologies, which may constrain focal firms in exploiting and building on co-owned technologies. We examine the appropriation effects of co-patenting in greater detail in the firm performance analysis.

\subsection{Firm-Level Analyses.}

We now turn to the analysis of financial performance - market valuation. Table 3 shows descriptive statistics of the variables used in the analyses. The table shows a positive bivariate correlation between the stock of university co-patenting and Tobin's q. In contrast, the stocks of intra-industry and inter-industry co-patenting are negatively correlated with the level of Tobin's q. Furthermore, it is striking that most technology-related variables (patents/R\&D, R\&D/assets, citations/patents) are negatively correlated with the intra-industry co-patent variable. Co-patenting appears to be associated with a lower score on most of the firm-level measures of technological strength, suggesting that technologically weaker firms engage more in intra-industry co-patenting. Our analysis aims to factor out this effect by controlling for these technological features and by exploiting the time ordering of co-patenting strategies and their informational effect on market valuation (the 2-year lag between co-patent applications and market valuation). We return to this issue in the discussion section. The correlations between the other independent variables are relatively low and do not raise 
multicollinearity concerns, with the exception of the control variables, technological diversification and firm size.

\section{INSERT TABLE 3}

Table 4 shows the results of the analyses on market valuation. Model 1 excludes the focal co-patenting variables and Model 2 shows the results when these are added. Consistent with prior research (e.g. Hall et al., 2005; Belenzon, 2011), Model 1 shows that R\&D intensity, the ratio of patents to $\mathrm{R} \& \mathrm{D}$, the citation ratio (at the $10 \%$ level), and the ratio of self-citations have positive and significant coefficients. Firms that exhibit greater technology diversification show significantly smaller levels of Tobin's q, which may reflect an investor preference for focusing on a set of core technologies and businesses. Larger firms have significantly higher values of Tobin's q.

In Model 2, we observe a negative and significant coefficient for the stock of copatents with intra-industry partners. The estimated coefficient implies that a standard deviation (0.032) change in the share of co-patents with intra-industry partners is associated with a reduction in Tobin's q of approximately 10\%. In contrast, co-patenting with interindustry partners has a positive, marginally significant effect on market valuation. Copatenting with universities has a strongly significant coefficient and suggests an association with Tobin's q whereby a standard deviation change in university co-patenting enhances or decreases q by roughly 6 percentage points. When we estimate random effects models rather than OLS models with clustered standard errors, smaller but significant coefficients are estimated for university and intra-industry co-patenting, while the coefficient on interindustry co-patenting becomes insignificant. In sum, the ranking of effects is fully in line with the view emerging from our interviews that IP sharing is unlikely to hamper appropriation if it concerns collaboration with universities, and is more likely to affect appropriation in intra-industry partnerships than in inter-industry partnerships. 
We further explored the correlation between market valuation and co-patenting with industry partners by examining the potential differential effects depending on the size of the partner firm. There are two alternative and non-exclusive reasons to expect variation in the negative relationship between intra-industry co-patenting and market valuation depending on the size of the partner firm. On the one hand, co-owned technology in the hands of a smaller partner firm is more likely to be transferred to a potential competitor as the firm becomes a takeover target or loses the fight for survival that a smaller firm habitually faces. On the other hand, co-owned technology in the hands of a larger partner is more likely to be used in competition with the focal firm as the partner firm grows and diversifies into other related businesses. ${ }^{17}$ Some of these businesses may well enter into competition with the focal firm. We, therefore, distinguished between co-patent shares with large and small partner firms, both for intra-industry and for inter-industry partners. We classified partner firms as large or small if their patent stock was larger or smaller than the median across all partners in the sample. Name harmonization algorithms (Van Looy et al., 2006) are used to collect patent data for partnering firms. Results indicated no significant effect of the two types of interindustry co-patenting, while intra-industry co-patenting coefficients were significant and negative both for small and for large partners. The intra-industry co-patenting coefficient for small partners was more strongly negative but not significantly different from the coefficient for large partners. We conclude that our analysis is not able to distinguish between the two explanations for potential differential effects of partner size; both considerations may play a role simultaneously.

\section{INSERT TABLE 4}

\section{Discussion}

\footnotetext{
${ }^{17}$ We thank Henry Chesbrough for this suggestion.
} 
Relying on both qualitative and quantitative data, this paper explores the role and performance implications of co-patents. Our findings provide a richer understanding of the challenges and opportunities that firms must confront when faced with strategic decisions concerning IP ownership in open innovation activities such as collaborative R\&D. First, we show that the challenge to appropriate value from sharing IP ownership depends on the type of partner involved. Second, we provide initial indications that engaging in co-patenting arrangements with collaborative partners may create value. Below, we discuss how our findings enrich our understanding of (i) the value-appropriation challenges of co-patenting and (ii) the value-creation opportunities of such arrangements. Subsequently, we point to the main limitations of our study and identify interesting avenues for future research on open innovation in general and co-patenting in particular.

\subsection{Challenges of Appropriating Value from Co-Patenting Activities.}

In line with previous research (Belderbos et al., 2010; Hagedoorn, 2003), our findings show that, in general, co-ownership of patented inventions presents important challenges in appropriating value. However, making a more fine-grained distinction between different types of partner (i.e. intra-industry, inter-industry, and university), we observe that these appropriation challenges are most pronounced when firms co-patent with firms situated within the same industry. This finding suggest that, to assess the extent to which co-patenting may restrict a firm's ability to reap the commercial benefits of collaborative R\&D efforts, it is important to consider the extent to which partners operate in overlapping exploitation domains. When both partners are active in different exploitation domains, as is likely the case with inter-industry partners, sharing ownership of the knowledge accruing from collaborative $\mathrm{R} \& \mathrm{D}$ is less likely to restrict their ability to appropriate the commercial benefits of the technology at hand. In contrast, when firms are active within the same industry, there is a 
high likelihood that - for a certain number of application domains - shared IP is associated with competing exploitation strategies, reducing value appropriation for the focal firm.

At the same time, we observe a significant positive relationship between co-patents with universities and market valuation. This result is likely to derive from the lack of appropriation risks from co-patenting with these types of partner. In our interviews, it was argued that firms sometimes allow universities to co-patent in order to send out strong signals that embedded relationships exist between the focal firm and universities, and that copatenting carries no implication that universities seek to commercialize the technologies. Hence, co-patenting places the focal firm in a favorable position with respect to absorbing new knowledge from this particular type of partner - thus generating, in all likelihood, relatively strong investor responses. In addition, previous research (e.g. Belderbos et al., 2004. Faems et al., 2005) has indicated that collaboration with universities is especially relevant for developing products or services of a more novel nature. Higher levels of novelty and access to valuable complementary resources combined with less 'competition' in terms of value appropriation is likely to generate the observed positive performance effects of copatenting with universities.

\subsection{Value Creation and Co-Patenting.}

Research on the governance of technology alliances has provided evidence that the initial contractual design of technology partnerships can have important value-creation implications. Several scholars (e.g. Anderson \& Dekker, 2005; Sampson, 2004), for instance, show that misalignment between transactional characteristics and contract complexity may substantially hamper partners' ability to generate value within alliances. Making a conceptual distinction between narrow and broad contractual interface structures, Faems et al. (2008) demonstrate that the content of the contract can have important ramifications in terms of sense making and 
trust building between partners in $\mathrm{R} \& \mathrm{D}$ alliances, which subsequently influence partners' ability to jointly resolve unexpected technological problems.

Focusing on the particular issue of contractual IP arrangements, our interviewees suggested that ex-ante negotiation of co-patenting agreements may have positive value creation implications as it (i) reduces ex-ante knowledge appropriation concerns for knowledge domains that do not clearly belong to one of the partners involved and (ii) fosters trust. Moreover, our empirical data provide some preliminary indications of value creation. Using forward citations as an indicator of technological performance, we observed that copatents with inter-firm and intra-firm industry partners receive more citations than individually-owned patents, albeit that this effect fades when introducing the number of inventors. At the same time, self-citations are negatively correlated when co-patenting implies industrial partners, which is consistent with the appropriation challenges discussed above. This indicates that firms are less likely to further develop co-owned technology internally, although such consecutive developments are often crucial in appropriating economical returns for their innovation efforts as demonstrated by Hall et al. (2005) and, more recently, by Belenzon (2012). Whether this is inspired by opportunity cost considerations (which may favor fully owned developments), restrictions on further development related to the IP sharing arrangement, or difficulties in terms of mobilizing required capabilities (including partners) remains to be investigated further.

\subsection{Limitations and Future Research.}

Whilst these results provide valuable insights into the value-appropriation and value-creation consequences of co-patents, we acknowledge the limitations of our study and emphasize the need for additional research. First, interviewees stressed the possibility to contractually mitigate the risks of value appropriation related to co-patents. In particular, they mentioned that, through negotiating clear rules about the division of exploitation rights concerning co- 
owned knowledge, firms may be able to reduce the risk of co-patents triggering competitive threats within their own market domains.

'Inter-firm collaboration can result in co-ownership of IP. [However], we will make sure that the exploitation rights on this co-owned IP are clearly divided among the partners.'

In other words, they suggest that partners may choose to co-own knowledge but, at the same time, contractually divide its exploitation rights. These interview insights suggest that, to further improve our understanding of appropriating value from different collaborative IP arrangements, it is not only important to look at the type of partner involved in copatenting activities but also to assess how the exploitation rights over such co-owned knowledge are distributed among the partners involved. However, obtaining information on exploitation rights remains an important challenge. In contrast to information on co-owned IP, which is publicly disclosed, contractual information on exploitation rights tends to be regarded by firms as highly sensitive information. Nevertheless, some scholars (e.g. Carson \& John, 2013; Hagedoorn \& Hesen, 2007; Elfenbein \& Lerner, 2003 and 2012) have previously demonstrated that it is possible to construct relatively large datasets on contractual agreements concerning R\&D collaborations. We, therefore, encourage future research that will provide in-depth insights into the division of co-owned exploitation rights and its relationship with performance. This will address one of the main limitations of our research: that we were unable to distinguish between collaborative technology development efforts, coownership of the outcome of the joint technology development efforts (co-patents), and the precise exploitation rights assigned to partners.

Our empirical results do raise the question as to why firms engage in technology agreements that over time reduce their market value compared to sole ownership. A potential explanation is that these firms face severe constraints with technology development efforts. The reason for partnering in the first instance is that they need access to the partner's 
technological knowledge. Sole ownership of the co-developed knowledge might not be feasible since the partner may well be unwilling to relinquish control, forcing partners to coown the technology. As Hagedoorn (2003) previously indicated, collaboration and IP sharing may be the only route to successful invention in particular circumstances.

A related issue concerns the possible reverse effect from financial performance to copatenting: financially and technologically weaker firms may be more likely to engage in copatenting strategies. In our interviews, we found some indications of such an effect. First, it was stressed that, the stronger the bargaining power of the firm within a collaborative partnership, the more likely it is able to negotiate sole ownership of strategically important foreground IP. Firms with less bargaining power, however, are more likely to be forced into a co-ownership arrangement with competitors involving knowledge generated during the collaboration that may have strategically important potential:

'In general, we try to avoid co-patents. When you are in a strong position, you can negotiate away co-patents. When you face a strong partner, you might not have the necessary power to do this.'

'The negotiation position influences the division of foreground IP. The stronger the bargaining position, the more likely you are able to claim sole ownership and the less likely you need to give the other partner shared ownership.'

This suggests that weaker market and technological performance may decrease firms' bargaining power in collaborative $\mathrm{R} \& \mathrm{D}$ partnerships with intra-industry partners, resulting in increased sharing of co-patents with intra-industry partners. While we found some indications that financially and technologically weaker firms are more likely to co-patent, we argue that the time lags and controls included in the market value analysis suggest it is unlikely that this type of selection can explain the partial correlations observed. Since analysis of the antecedents of co-patenting is beyond the scope of this current paper, we see investigation of the decision to share IP rights or engage in specific arrangements to share exploitation rights as a valuable avenue for future research. 
Finally, given our focus on large R\&D-intensive firms with relatively large patent portfolios, our findings are not representative of the specific challenges that small firms face when considering R\&D collaboration and IP sharing on co-developed technologies. We suggest that future research efforts focus on examining co-patenting in smaller firms specifically. Finally, the different legal framework and institutions relevant to EPO and USPTO patents, with their differential consequences for IP sharing, is a source of variation that could be exploited in future research comparing firms' strategies in the two patent jurisdictions.

\section{Conclusion.}

Engaging in open-innovation efforts not only triggers opportunities for value creation but also presents substantial challenges in seeking to appropriate this value. In this paper, we explored the role of joint patent ownership in addressing this 'openness paradox.' We believe that our findings will inspire academic scholars to further examine the value-appropriation liabilities as well as the value-creation opportunities of co-patenting and collaboration arrangements. In addition, we trust that our insights will help practitioners to further optimize their collaborative IP strategies with different types of partner.

\section{References.}

Ahuja, G., 2000. The duality of collaboration: inducements and opportunities in the formation of interfirm linkages. Strategic Management Journal 21, 317-343.

AIPPI., 2007. Summary Report Question Q194. The Impact of Co-Ownership of Intellectual Property Rights on their Exploitation.

Albert, M.B., Avery, D., Narin, F., McAllister, P., 1991. Direct validation of citation counts as indicators of industrially important patents. Research Policy 20, 251-259.

Alcacer, J., Gittelman, M., 2006. Patent Citations as a Measure of Knowledge Flows: The Influence of Examiner Citations. The Review of Economics and Statistics 88, 774-779. 
Alcacer, J., Gittelman, M., Sampat, B.N., 2009. Applicant and Examiner Citations in U.S. Patents: An Overview and Analysis. Research Policy 38, 415-427

Azzaleo A., Landoni P., Van Looy B., 2012. Exploring indicators of Open Innovation: the role of co-patents. Paper presented at the STI Conference Leiden, 2010. KU Leuven - MSI Working Paper, 2012.

Arora, A., Belenzon, S., Rios, L.A., 2013. Make, Buy, Organize: The Interplay Between Research, External Knowledge, and Firm Structure. Strategic Management Journal, forthcoming. (DOI: 10.1002/smj.2098)

Arundel, A., Kabla I., 1998. What percentage of innovations are patented? Empirical estimates from European firms. Research Policy 27, 127-141.

Basberg B., 1987. Patents and the measurement of technological change: A survey of the literature. Research Policy 16, 131-141.

Belderbos, R., Carree, M., Diederen, B., Lokshin, B., Veugelers, R., 2004a. Heterogeneity in R\&D collaboration strategies. International Journal of Industrial Organization 22, 1237-1263.

Belderbos, R., Carree, M., Lokshin, B., 2004b. Cooperative R\&D and firm performance. Research Policy 33, 1477-1492.

Belderbos, R., Faems, D., Leten, B., Van Looy, B., 2010. Technological Activities and Their Impact on the Financial Performance of the Firm: Exploitation and Exploration within and between Firms. Journal of Product Innovation Management 27, 869-882.

Belenzon S. 2011., Cumulative innovation and market value: evidence from patent citations, The Economic Journal 122, 265-285.

Benner M., Ranganathan R., 2012. Offsetting illegitimacy? How pressures from securities analysts influence incumbents in the face of new technologies. Academy of Management Journal 55, 213-233.

Blundell, R., Griffith, R., van Reenen, J., 1999. Market Share, Market Value, and Innovation in a Panel of British Manufacturing Firms. Review of Economic Studies 66, 529-554.

Carlson, D., Barney, J.R., 1999. The division of rights among joint inventors: Public policy concerns after ehticon versus surgical. The Journal of Law and Technology 39, 251.

Carson, S.J., John, G., 2013. A theoretical and empirical investigation of property rights sharing in outsourced research, development, and engineering relationships. Strategic Management Journal 34, 1065-1085.

Carson, S.J., Madhok, A., Varman, R., John, G., 2003. Information processing moderators of the effectiveness of trust-based governance in interfirm $R \& D$ collaboration. Organization Science 14, 45-56.

Cassiman, B., 2008. Research Joint Ventures, in the New Palgrave Dictionary of Economics, second edition. 
Cassiman, B., Veugelers, R., 2006. In search of complementarity in innovation strategy: Internal R\&D and external knowledge acquisition. Management Science 52, 68-82.

Chesbrough, H., 2003. The era of open innovation. Mit Sloan Management Review 44, 3541.

Chesbrough, H., 2006. Open Innovation: A new paradigm for understanding industrial innovation, in Chesbrough, H., Vanhaverbeke, W., West, J. (Eds.), Open Innovation: Researching a New Paradigm. Oxford University Press, Oxford, 1-12.

Chesbrough, H., Rosenbloom, R., 2002. The role of the business model in capturing value from innovation: evidence from Xerox Corporation's technology spin-off companies. Industrial and Corporate Change 11, 529-555.

Czarnitzki, D., Hall, B.H., Oriani, R., 2006. The Market Valuation of Knowledge Assets in US and European Firms. In: The Management of Intellectual Property, ed. D. Bosworth, and R. Webster. Cheltenham, UK: Edward Elgar, 111-131.

Di Minin, A., Faems, D., 2013. Building appropriation advantage: An introduction to the special issue on intellectual property management. California Management Review 55, 7-14.

Doz, Y.L., 1996. The evolution of cooperation in strategic alliances: initial conditions or learning processes? Strategic Management Journal 17, 55-83.

Dyer, J.H., Singh, H., 1998. The relational view: cooperative strategy and sources of interorganizational competitive advantage. Academy of Management Review 23, 660-679.

Faems, D., Janssens, M., Madhok, A., Van Looy, B., 2008. Toward an Integrative Perspective on Alliance Governance: Connecting Contract Design, Trust Dynamics, and Contract Application. Academy of Management Journal 51, 1053-1078.

Faems, D., Janssens, M., van Looy, B., 2007. The initiation and evolution of interfirm knowledge transfer in R\&D relationships. Organization Studies 28, 1699-1728.

Faems, D., Van Looy, B., Debackere, K., 2005. Interorganizational collaboration and innovation: Toward a portfolio approach. Journal of Product Innovation Management 22, 238-250.

Fleming, L., Sorenson, O., 2004. Science as a map in technological search. Strategic Management Journal 25, 909-928.

Fosfuri, A., Helmers, C., Roux, C., 2012. Are joint patents collusive? Evidence from the US and Europe. Discussion Paper 2012-035, Tilburg University, Tilburg Law and Economic Center.

Gambardella, A., Harhoff, D., Verspagen, B., 2008. The Value of European Patents. CEPR discussion paper no. 6848 . 
Gnyawali, D. R., Park, B., 2009. Co-opetition and technological innovation in small and medium-sized enterprises: A multilevel conceptual model. Journal of Small Business Management 47, 308-330.

Gnyawali, D. R., Park, B., 2011. Co-opetition between giants: Collaboration with competitors for technological innovation. Research Policy 40, 650-63.

Goossen, M., 2013. Sharing intellectual property rights in an era of open innovation: An exploratory study on co-assigned patents. Mimeo.

Griliches, Z., 1981. Market Value, R\&D and Patents. Economic Letters 7, 183-187.

Griliches, Z., Mairesse J., 1984. Productivity and R\&D at the firm level. In Z. Griliches (ed.): R\&D, Patents and Productivity, 339-74. Chicago, University of Chicago Press.

Griliches, Z. 1990. Patent Statistics as Economic Indicators: A Survey. Journal of Economic Literature 28, 1661-1707.

Hagedoorn, J., 2003. Sharing intellectual property rights - an exploratory study of joint patenting amongst companies. Industrial and Corporate Change 12, 1035-1050.

Hagedoorn, J., Van Kranenburg, H., Osborn, R.N., 2003. Joint patenting amongst companies: Exploring the effects of inter-firm R\&D partnering and experience. Managerial and Decision Economics 24, 71-84.

Hall, B., Jaffe, A., Trajtenberg, M., 2005. Market Value and Patent Citations. Rand Journal of Economics 36, 16-38.

Hall, B.H., Oriani R., 2006. Does the market value R\&D investment by European firms? Evidence from a panel of manufacturing firms in France, Germany, and Italy. International Journal of Industrial Organization 5, 971-993.

Hall, B.H., Thoma, G., Torrisi, S., 2007. The market value of patents and R\&D: Evidence from European firms. NBER Working Paper No. 13426, Cambridge, MA.

Harhoff, D., Narin, F., Scherer, F.M., Vopel, K., 1999. Citation Frequency and the Value of Patented Innovation. Review of Economics and Statistics 81, 511-515.

Harhoff, D., Scherer, F., Vopel, K., 2003. Citations, Family Size, Opposition and the Value of Patent Rights - Evidence from Germany. Research Policy 32, 1343-1363.

Harhoff, D., Wagner, S., 2009. The duration of patent examination at the European Patent Office. Management Science 55, 1969-1984.

Heiman, B.A., Nickerson, J.A., 2004. Empirical evidence regarding the tension between knowledge sharing and knowledge expropriation in collaborations. Managerial and Decision Economics, 25. 
Henderson, R., Jaffe, A.B., Trajtenberg, M. 1998. Universities as a source of commercial technology: A detailed analysis of university patenting, 1965-1988. The Review of Economics and Statistics, 119-127.

Henkel, J., 2006. Selective revealing in open innovation processes: The case of embedded Linux. Research Policy 35, 953-969.

Jaffe, A., Lerner, J. 2004. Innovation and Its Discontents: How Our Broken Patent System Is Endangering Innovation and Progress, and What to Do about It. Princeton, NJ: Princeton University Press.

Jaffe, A.B., Trajtenberg, M., Fogarty, M. Knowledge spillovers and patent citations: Evidence from a survey of inventors. American Economic Review 90, 215-218.

Laursen, K., Salter, A., 2005. The paradox of openness of knowledge for innovation.

Laursen, K., Salter, A., 2006. Open for innovation: The role of openness in explaining innovation performance among UK manufacturing firms. Strategic Management Journal 27, 113-150.

Levin, R., Klevorick, A., Nelson, R., Winter, S., 1987. Appropriating the Returns from Industrial Research and Development. Brookings Papers on Economic Activity 3, 783-831.

Madhok, A., Tallman, S.B., 1998. Resources, transactions and rents: managing value through interfirm collaborative relationships. Organization Science 9, 326-339.

Mansfield, E., 1986. Patents and Innovation: An Empirical Study. Management Science 32, 173-181.

Merges, R.P., Locke, L.A., 1990. Co-ownership of patents: A comparative and economic view. Journal of the Patent and Trademark Office Society 72.

Mowery, D. C., Oxley, J.E., Silverman, B.S., 1996. Strategic alliances and interfirm knowledge transfer. Strategic Management Journal, 17: 77-91.

Pakes, A., 1995. On Patents, R\&D, and the Stock Market Rate of Return, Journal of Political Economy, 93, 390-409.

Paradiso, R.J., Pietrowski, E., 2009. Dilemmas of joint patent ownership. New Jersey Law Journal 197, 912-913.

Pavitt, K., 1985. Patent Statistics as Indicators of Innovative Activities: Possibilities and Problems. Scientometrics 7, 77-99.

Quillen, C., Webster, O., 2001. Continuing Patent Applications and Performance of the US Patent Office. Federal Circuit Bar Journal 11, 1-21.

Reitzig, M., 2004. Improving patent valuations for management purposes — validating new indicators by analyzing application rationales. Research Policy, 33: 939-957. 
Ritala, P., Hurmelinna-Laukkanen, P., 2009. What's in it for me? Creating and appropriating value in innovation-related coopetition. Technovation 29, 819-28.

Roach, M., Cohen, W.M., 2013. Lens or Prism? Patent Citations as a Measure of Knowledge Flows from Public Research. Management Science 59, 504-525.

Rosenkopf, L., Nerkar, A., 2001. Boundary spanning, exploration, and impact in the optical disk industry. Strategic Management Journal, 22, 287-306.

Schankerman, M., Pakes, A., 1986. Estimates of the value of patent rights in European countries during the post-1950 period. The Economic Journal 96, 1052-1076.

Schmoch, U., Laville, F., Patel, P., Frietsch, R., 2003. Linking Technology Areas to Industrial Sectors: Final Report to the European Commission , DG Research.

Scotchmer, S., 1991. Standing on the shoulders of giants: Cumulative research and the patent law. The Journal of economic Perspectives, 5: 29-41.

Sorensen, J.B, Stuart, T.E., 2000. Aging, obsolescence and organizational innovation. Administrative Science Quarterly 45, 81-112.

Teng, B-S., 2007. Managing intellectual property in R\&D alliances. International Journal of Technology Management 38, 160-177.

Tether, B., 2002. Who co-operates for innovation, and why: An empirical analysis. Research Policy 31: 947-967.

Trajtenberg, M., 1990. A Penny for your quotes: Patent citations and the value of innovations. RAND Journal of Economics 21, 172-187.

Van Looy, B., Du Plessis, M., Magerman, T., 2006. Data production methods for harmonized patent indicators: assignee sector allocation. EUROSTAT Working Paper and Studies, Luxemburg.

Van Looy B., Magerman T., Debackere K., 2007. Developing technology in the vicinity of science: An examination of the relationship between science intensity (of patents) and technological productivity within the field of biotechnology. Scientometrics, 70, 441-458

Van Pottelsberghe de la Potterie, B., François, D., 2006. The Cost Factor in Patent Systems. EPO working paper CEB 06-002.

Vanhaverbeke, W., 2006. The interorganizational context of open innovation, in Chesbrough, H., Vanhaverbeke, W., West, J. (Eds.), Open Innovation: Researching a New Paradigm, 205219.

Veugelers, R., Cassiman, B., 2005. R\&D Cooperation between Firms and Universities: Some empirical evidence from Belgium, The International Journal of Industrial Organization 23, 355-379. 
West, J., 2006. Does Appropriability Enable or Retard Open Innovation? in Henry Chesbrough, Wim Vanhaverbeke and Joel West, eds., Open Innovation: Researching a New Paradigm, Oxford: Oxford University Press, 2006, 109-133. 
Table 1. Trends in co-patenting activity (164 sample firms).

\begin{tabular}{lrrrrrrrrr}
\hline year & $\mathbf{1 9 9 5}$ & $\mathbf{1 9 9 6}$ & $\mathbf{1 9 9 7}$ & $\mathbf{1 9 9 8}$ & $\mathbf{1 9 9 9}$ & $\mathbf{2 0 0 0}$ & $\mathbf{2 0 0 1}$ & $\mathbf{2 0 0 2}$ & $\mathbf{2 0 0 3}$ \\
Co-patents - inter-industry & 166 & 207 & 189 & 209 & 176 & 188 & 147 & 79 & 49 \\
\% total & 1.6 & 2.0 & 1.7 & 2.0 & 1.6 & 1.9 & 1.7 & 1.2 & 1.1 \\
& & & & & & & & & \\
Co-patents - intra-industry & 120 & 98 & 118 & 105 & 122 & 138 & 103 & 69 & 52 \\
\% total & 1.2 & 0.9 & 1.1 & 1.0 & 1.1 & 1.4 & 1.2 & 1.1 & 1.1 \\
Co-patents - universities & 15 & 20 & 16 & 16 & 11 & 21 & 9 & 4 & 7 \\
\% total & 0.15 & 0.19 & 0.15 & 0.15 & 0.10 & 0.21 & 0.10 & 0.06 & 0.15 \\
& & & & & & & & & \\
All patent grants & 10112 & 10424 & 10804 & 10607 & 10707 & 10043 & 8862 & 6543 & 4619 \\
\hline
\end{tabular}

Table 2. Robust Poisson Regression of Forward Citations Received (patent level)

\begin{tabular}{|c|c|c|c|c|c|}
\hline & $\begin{array}{l}\text { Model } 1 \\
\text { all cites }\end{array}$ & $\begin{array}{l}\text { Model } 2 \\
\text { all cites }\end{array}$ & $\begin{array}{l}\text { Model } 3 \\
\text { all cites }\end{array}$ & $\begin{array}{l}\text { Model } 4 \\
\text { selfcites }\end{array}$ & $\begin{array}{c}\text { Model } 5 \\
\text { nonselfcites }\end{array}$ \\
\hline \multirow[t]{2}{*}{ copatent - interindustry } & $0.114^{* *}$ & $0.119 * * *$ & 0.025 & $-0.488^{* * *}$ & $0.142 * * *$ \\
\hline & {$[0.046]$} & {$[0.046]$} & {$[0.046]$} & {$[0.052]$} & {$[0.051]$} \\
\hline \multirow[t]{2}{*}{ copatent - intraindustry } & $0.130 * * *$ & $0.129 * * *$ & 0.021 & $-0.322 * * *$ & $0.118 * * *$ \\
\hline & {$[0.043]$} & {$[0.043]$} & {$[0.043]$} & {$[0.073]$} & {$[0.045]$} \\
\hline \multirow[t]{2}{*}{ copatent - universities } & 0.213 & 0.179 & 0.084 & -0.151 & 0.159 \\
\hline & {$[0.163]$} & {$[0.164]$} & {$[0.165]$} & {$[0.178]$} & [0.183] \\
\hline \multirow[t]{2}{*}{ backward patent citations } & & $0.021 * * *$ & $0.019^{* * * *}$ & $0.019 * * *$ & $0.019 * * *$ \\
\hline & & {$[0.002]$} & {$[0.002]$} & {$[0.002]$} & {$[0.002]$} \\
\hline \multirow[t]{2}{*}{ non-patent citations } & & $0.038 * * *$ & $0.037^{* * *}$ & $0.024 * * *$ & $0.042 * * *$ \\
\hline & & {$[0.005]$} & {$[0.005]$} & {$[0.005]$} & {$[0.005]$} \\
\hline \multirow[t]{2}{*}{ number of technology fields } & & 0.066 & 0.055 & 0.093 & 0.046 \\
\hline & & {$[0.107]$} & {$[0.107]$} & {$[0.166]$} & {$[0.118]$} \\
\hline \multirow[t]{2}{*}{ number of inventors } & & & $0.058^{* * * *}$ & $0.088 * * *$ & $0.047 * * *$ \\
\hline & & & {$[0.003]$} & {$[0.003]$} & [0.003] \\
\hline 3-digit IPC dummies & Included & Included & Included & Included & Included \\
\hline firm dummies & Included & Included & Included & Included & Included \\
\hline year dummies & Included & Included & Included & Included & Included \\
\hline Observations & 85706 & 85706 & 85706 & 85706 & 85706 \\
\hline Loglikelihood & -461334 & -464959 & -467367 & -183918 & -404446 \\
\hline Pseudo R2 & 0.129 & 0.133 & 0.14 & 0.115 & 0.151 \\
\hline
\end{tabular}


Table 3. Market valuation model: means, standard deviations and correlations

\begin{tabular}{|c|c|c|c|c|c|c|c|c|c|c|c|c|}
\hline & & mean & st dev & 1 & 2 & 3 & 4 & 5 & 6 & 7 & 8 & 9 \\
\hline 1 & Tobin's q (log transformed) & 0.260 & 0.772 & & & & & & & & & \\
\hline 2 & intraindustry copatenting & 0.022 & 0.032 & -0.169 & & & & & & & & \\
\hline 3 & interindustry copatenting & 0.022 & 0.033 & -0.260 & 0.471 & & & & & & & \\
\hline 4 & university copatenting & 0.003 & 0.010 & 0.243 & 0.029 & -0.052 & & & & & & \\
\hline 5 & $\mathrm{R} \& \mathrm{D} /$ assets & 0.064 & 0.049 & 0.466 & -0.014 & -0.233 & 0.148 & & & & & \\
\hline 6 & patents/RD & 0.172 & 0.172 & -0.069 & -0.131 & 0.001 & -0.161 & -0.249 & & & & \\
\hline 7 & citations/patents & 6.518 & 4.074 & 0.452 & -0.117 & -0.205 & 0.057 & 0.438 & -0.227 & & & \\
\hline 8 & selfcitations/citations & 0.246 & 0.114 & 0.182 & -0.087 & -0.151 & 0.039 & -0.010 & 0.189 & 0.020 & & \\
\hline 9 & firm size & 15.617 & 1.267 & -0.155 & -0.040 & 0.097 & -0.002 & -0.258 & -0.130 & 0.105 & 0.064 & \\
\hline 10 & technology diversification & 4.132 & 0.879 & -0.408 & -0.119 & 0.181 & -0.158 & -0.406 & 0.242 & -0.283 & 0.085 & 0.714 \\
\hline
\end{tabular}

$\mathrm{N}=1059$ 
Table 4. Copatenting and Market valuation (Tobin's q)

\begin{tabular}{lcc}
\hline & Model 1 & Model 2 \\
\hline intraindustry copatenting t-2 & & $-3.185^{* * *}$ \\
& & {$[0.855]$} \\
interindustry copatenting t-2 & & $1.793^{*}$ \\
& & {$[0.991]$} \\
university copatenting t-2 & & $5.955^{* *}$ \\
& & {$[2.673]$} \\
R\&D/assets & $3.552^{* * *}$ & $3.823^{* * *}$ \\
& {$[1.076]$} & {$[1.034]$} \\
patents/RD t-2 & $0.748^{* * *}$ & $0.725^{* * *}$ \\
& {$[0.251]$} & {$[0.253]$} \\
citations/patents t-2 & $0.021^{*}$ & $0.021^{*}$ \\
& {$[0.012]$} & {$[0.012]$} \\
selfcitations/citations t-2 & $0.924^{* * *}$ & $0.950^{* * *}$ \\
& {$[0.312]$} & {$[0.306]$} \\
firm size & $0.137^{* * *}$ & $0.139^{* * *}$ \\
& {$[0.045]$} & {$[0.044]$} \\
techology diversification & $-0.310^{* * *}$ & $-0.336^{* * *}$ \\
& {$[0.084]$} & {$[0.085]$} \\
country dummies & included & included \\
year dummies & included & included \\
16 sector dummies & included & included \\
Observations (firms) & & \\
R squared & 1,059 & 1,059 \\
\hline
\end{tabular}

$*$ significant at $10 \%$; ** significant at $5 \%$; *** significant at $1 \%$

Note: results of OLS regression with firm-clustered standard errors 